Bangladesh J. Bot. 50(3): 747-753, 2021 (September) SpecialＤOI: https://doi.org/10.3329/bjb.v50i5.56425

\title{
DRYOPTERIS LIJIANXIUII (DRYOPTERIDACEAE), A NEW SPECIES FROM CHINA
}

\author{
XiaOjuan Li ${ }^{1}$, Xiao Wang ${ }^{1}$ and Wei LiU ${ }^{1} *$ \\ Qilu University of Technology [Shandong Academy of Sciences] \\ Shandong Analysis and Test Center, Jinan-250014, China
}

Keywords: China, Dryopteridaceae, Dryopteris, New species, SEM study, Spore ornamentation

\begin{abstract}
Dryopteris lijianxiuii X. J. Li, a new species of Dryopteris Adans. from Shandong, China, is described and illustrated. It is closer to D. lacera (Thunb.) O. Kuntze for its morphological and palynological characters of LM and SEM studies but differs by a number of characters, such as, the leaves rectangular roundlanceolate, apex acuminate, and without narrow sharply; sori ornamented in the upper or middle part of 1-3 pairs of pinnaes at the base of the leaf, and densely covered with the upper and middle pinnaes back; spore perispore with tuberculiform-rugulate protrusions, and surfaces with melting ice and snow ornamentation. The sp. nov. is described with LM and SEM characters of spore and fronds, compared with that of D. lacera (Thunb.) O. Kuntze and provided with photographs.
\end{abstract}

\section{Introduction}

Dryopteris Adans., one of the largest genera of Dryopteridaceae, with about 300 species (Wang and Dai 2010) is widely distributed all over the world, mostly in the Asian continent (especially China and the Himalayas, Japan, and North Korea) as the distribution center. China, with 167 species (60 endemic) of Dryopteris Adans. is regarded as the centre of distribution for this genus (Wu et al. 2013). This genus is rich in germplasm resources and species diversity. Previous research on taxonomy, palynology and morphology of Dryopteris (Li and Ma 1983, Li and Li 1988, Li 1985, Zhou et al. 1985, Ding et al. 1990, Chen 1990, Li et al. 1997, Lu et al. 2007, Fu et al. 2008, Wang and Dai 2010, Li et al. 2019) provided an important background that warrants the recognition of a new species of the genus.

\section{Materials and Methods}

The voucher specimens of the new species were collected from Zhengqishan Mountain, China and deposited in PE (Herbaria acronyms according to Thiers 2016).

Scanning electron microscopy (SEM) was used to study the micromorphology of spore and fronds. Samples were dehydrated and were then placed on aluminium stubs using double-sided adhesive tape and sputter coated with gold in a Hitachi E-1010 Ion Sputter Coater, following Wen and Nowicke (1999). The materials were subsequently observed and photographed under a SUPRATM55 SEM.

Dryopteris lijianxiuii X. J. Li, sp. nov.

Dryopteris lijianxiuii X. J. Li is closer to D. lacera (Thunb.) O. Kuntze by its morphological and palynological characters of LM and SEM study but differs by a number of characters, such as, the leaves were rectangular round-lanceolate, apex acuminate, and without narrow sharply; sori

*Author for correspondence: <liuwei0074@163.com>. 'Qilu University of Technology [Shandong Academy of Sciences], School of Pharmacy, Jinan-250014, China. 
were distributed in the upper or middle part of 1-3 pairs of pinnaes at the base of the leaf, and densely covered with the upper and middle pinnaes back; spore perispore with tuberculiformrugulate protrusions, and surfaces with melting ice and snow ornamentation.

Type specimen: China, Shandong Province, Weihai City, Zhengqishan Mountain, wet habitat, $37^{\circ} 33^{\prime} 34.73^{\prime \prime N}, 122^{\circ} 19^{\prime} 10.36 "$ E, 370 - 500 m a. s. 1., 22 August 1982, J. X. Li 822-1 (Holotype: PE, Isotype: SDCM). Fig. 1.

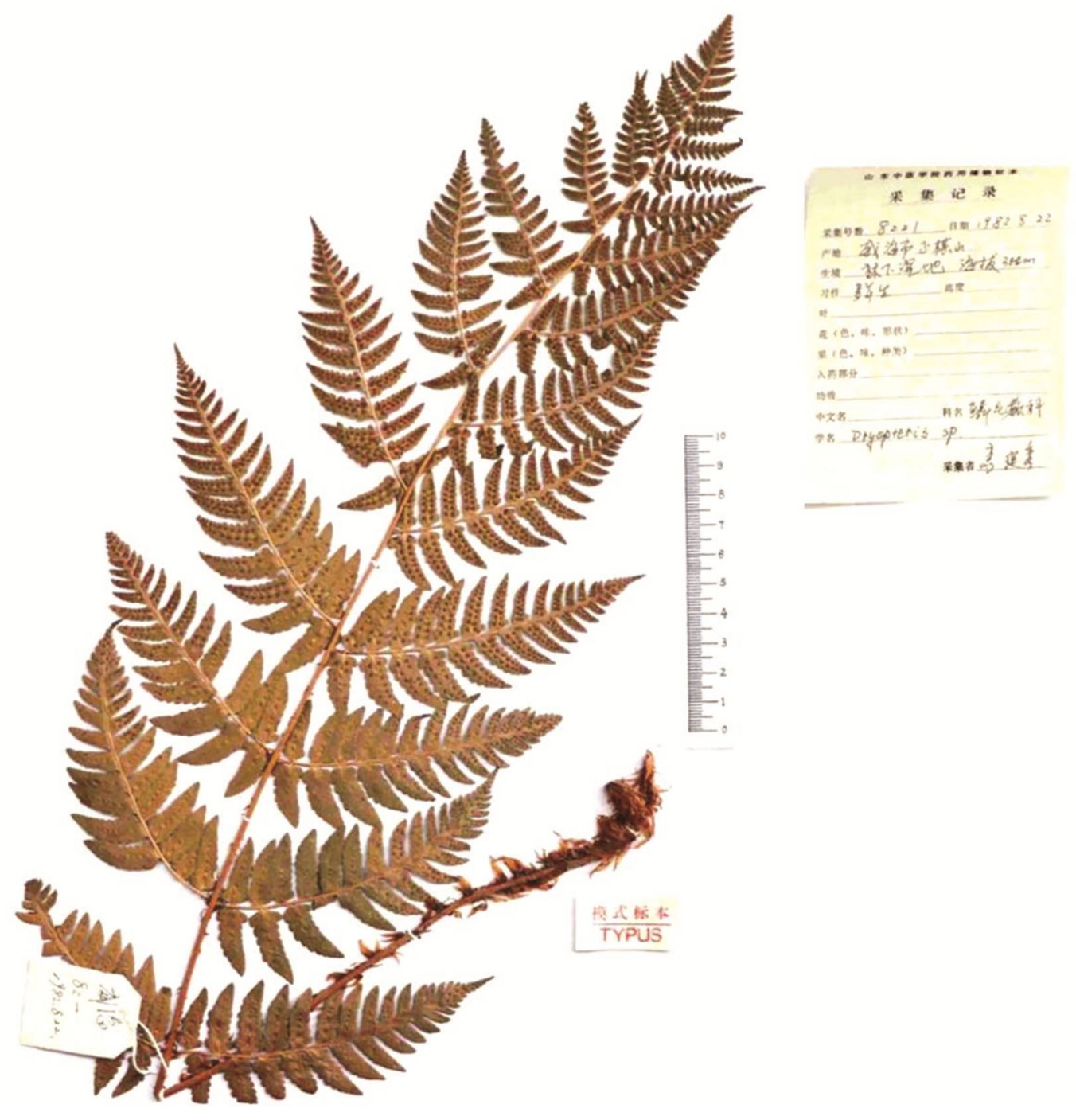

Fig. 1. A branch of Dryopteris lijianxiuii X. J. Li

Plants 60 - $65 \mathrm{~cm}$ tall. Rhizome erect or obliquely ascending. Fronds caespitose; stipes 15-20 $\mathrm{cm}$, stramineous, densely scaly together with stipe base, scales brown, lanceolate; margin serrate; lamina rectangular oblong, 40-45 × 18-20 cm, 2-pinnate-pinnatifid, apex acuminate; pinnae 12 pairs, shortly stalked, lanceolate, lower pinnae barely shortened, upper pinnae gradually contracted; 
small pinnate sickle-lanceolate, $2.5 \mathrm{~cm}$ long, $0.8-1 \mathrm{~cm}$ wide, short stalk or conjoined with rachis, with round and blunt teeth; lamina papery to leathery, yellow-green after drying. Rhachis and pinnate axis with brown linear-lanceolate toothed small scales; the veins concaved on both sides, pinnate, and branched on the lobes. Sori were distributed in the upper or middle part of 1-3 pairs of pinnaes at the base of the leaf, and densely covered with the upper and middle pinnaes back, lined up on each side of the main vein of the pinnule, slightly close to the main vein, indusia orbicular-reniform, entire. Spores symmetrical on both sides, single fracture, polar view oblong, equatorial view super semicircular, with perispore, spore perispore with tuberculiform-rugulate protrusions, and surfaces with melting ice and snow ornamentation. This species is known in Zhengqi Mountain, Weihai, Shandong Province, and usually grows between wet stone crevices under the forest (Tables 1 and 2).

Table 1. Comparison of leaf characters between two closest species of Dryopteris.

\begin{tabular}{|c|c|c|c|}
\hline Species & Distribution of sori & Voucher specimens & Fig. 2 \\
\hline D. lijianxiuii sp. nov. & $\begin{array}{l}\text { Sori distributed in the upper or middle part } \\
\text { of } 1-3 \text { pairs of pinnaes at the base of the } \\
\text { leaf, and densely covered with the upper } \\
\text { and middle pinnaes back }\end{array}$ & $\begin{array}{l}\text { Holotype } \\
\text { J. X. Li 822-1 }\end{array}$ & $\mathrm{A}, \mathrm{C}$ \\
\hline $\begin{array}{l}\text { D. lacera (Thunb.) } \\
\text { O. Kuntze }\end{array}$ & $\begin{array}{l}\text { Sori born only on the back of the } \\
\text { constricted part at the top of the leaf }\end{array}$ & $\begin{array}{l}\text { Voucher } \\
\text { J. X. Li } 850716\end{array}$ & $\mathrm{~B}, \mathrm{D}$ \\
\hline
\end{tabular}

Table 2. Comparison of spore morphological features between two closest species of Dryopteris.

\begin{tabular}{|c|c|c|c|}
\hline Species name & Ornamentation of perispore SEM characters & Voucher specimen & Fig. 3 \\
\hline D. lijianxiuii sp. nov. & $\begin{array}{l}\text { Spore perispore with tuberculiform-rugulate } \\
\text { protrusions, and surfaces with melting ice and snow } \\
\text { ornamentation. }\end{array}$ & $\begin{array}{l}\text { Shandong J. X. Li } \\
\text { 822-1 PE }\end{array}$ & A-D \\
\hline $\begin{array}{l}\text { D. lacera (Thunb.) } \\
\text { O. Kuntze }\end{array}$ & $\begin{array}{l}\text { Spore perispore with tuberculiform protrusions, and } \\
\text { surfaces with scaly ornamentation. }\end{array}$ & $\begin{array}{l}\text { Shandong J. X. Li } \\
850716 \text { SDCM }\end{array}$ & E-H \\
\hline
\end{tabular}

\section{Results and Discussion}

The sori were important part of the reproductive organs of ferns. The leaves (or pines, pinnule) with the sori are called sporophyll or fertile leaves, and the leaves without the sori are called nutrition or sterile leaves (Instituto botanico academiae sinicae instituto botanico borealioccidentali academiae sinicae edita 1974). The sori of D. lijianxiuii X. J. Li were distributed in the upper or middle part of 1-3 pairs of pinnaes at the base of the leaf (Fig. 2A), and densely covered with the upper and middle pinnaes back (Fig. 2C), which belongs to the sporophyll (fertile leaves); while the sori of D. lacera were only born on the back of the constricted part of the top of the leaf (Fig. 2D). D. lijianxiuii and D. lacera were similar in shape, but the fertile part of the sori were significantly different. Therefore, the distribution of sori on the leaves was the most important basis for distinguishing these two species. 

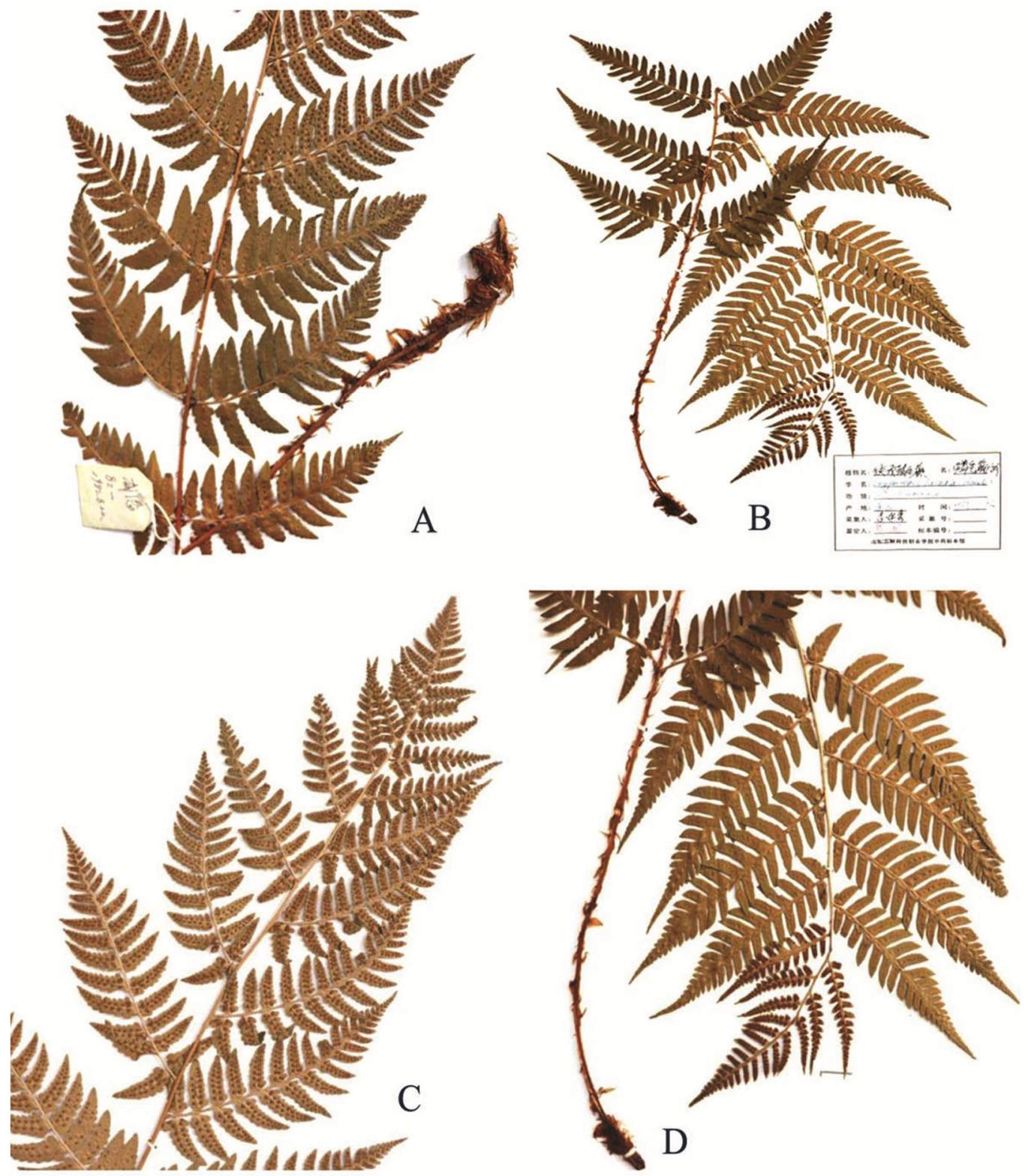

Fig. 2. The leaves of $D$. lijianxiuii sp. nov. and $D$. lacera. A. The sori of $D$. lijianxiuii were distributed in the upper or middle part of 1-3 pairs of pinnaes at the base of the leaf. B. The leaf of D. lacera. C. The sori of $D$. lijianxiuii densely covered with the upper and middle pinnaes back. D. The sori of $D$. lacera were only born on the back of the constricted part of the top of the leaf.

The study of the spore morphology and sporoderm pattern of pteridophytes by Zhang (1979), Zhang and $\mathrm{Xi}$ (1976), Zhang et al. (2012) is of great significance to the taxonomy of pteridophytes, not only as an important basis for finding their position in plant taxa, but also as an important 
voucher of the genetic relationship and phylogenetic evolutionary sequence between taxa and their relatives. Warre and Wagner (1974) proposed that the outer sporoderm pattern of pteridophytes can be used as an important basis for judging the evolutionary relationship of pteridophytes at the species and genus levels. In the same species, the mature spore morphology and wall ornamentation are consistent, its characteristics are stable, and there are differences between different species ( $\mathrm{Li}$ et al. 1997). Jermy believed that the spore morphology of pteridophytes contributes to the discovery of some new species. For example, Dryopteris guanchica of
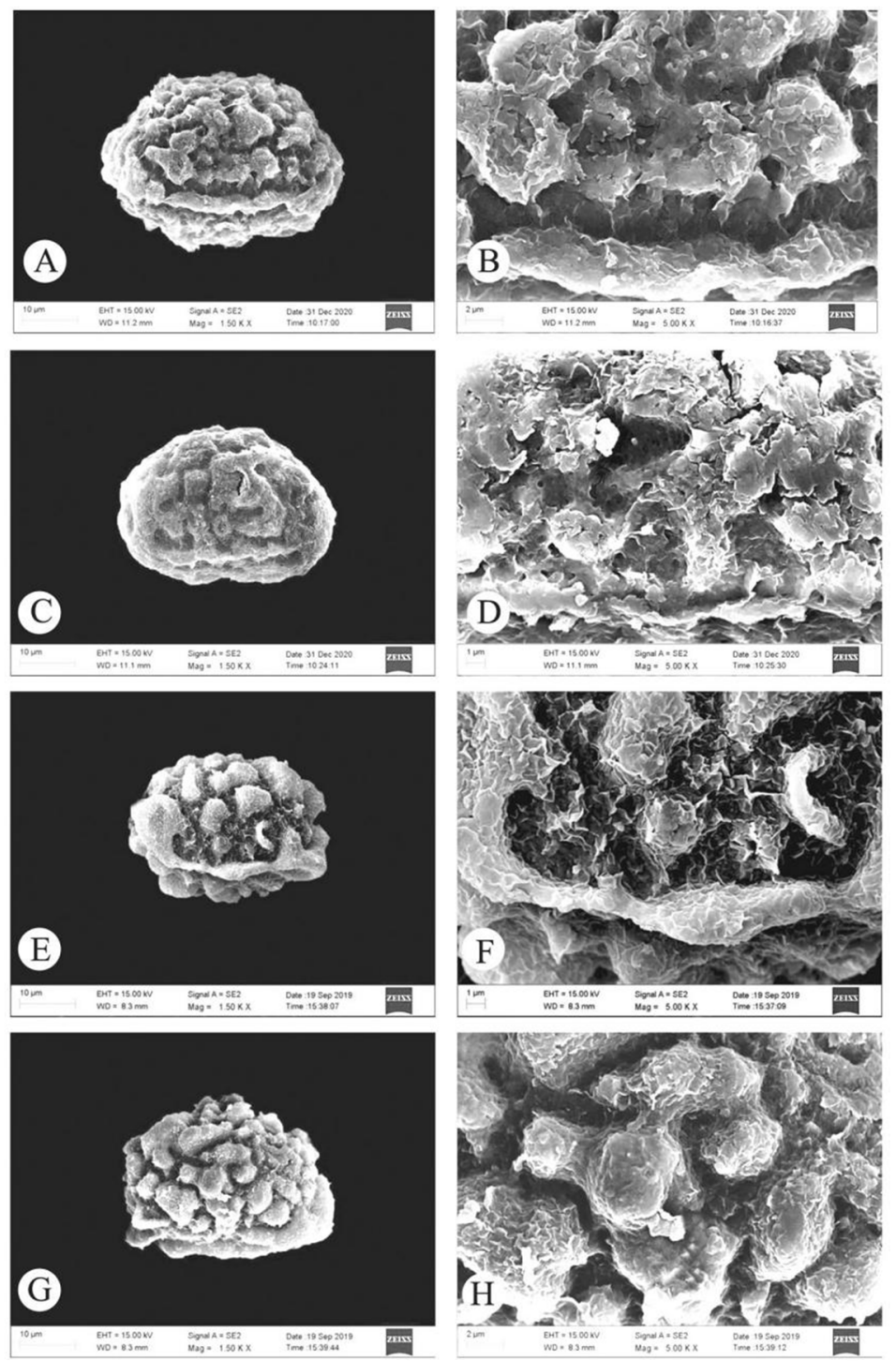

Fig. 3. SEM spore morphologies of two species of Dryopteris. A. Spore in polar view of D. lijianxiuii (1500×); B. Detail of spore in polar view of $D$. lijianxiuii (5000×); C. Spore in equatorial view of D. lijianxiuii (1500×); D. Detail of spore in equatorial view of $D$. lijianxiuii (5000x); E. Spore in polar view of D. lacera (1500×); F. Detail of spore in polar view of D. lacera $(5000 \times)$; G. Spore in equatorial view of D. lacera $(1500 \times)$; H. Detail of spore in equatorial view of D. lacera $(5000 \times)$. 
Dryopteris was a new species discovered through the ornamentation of the perispore wall (Jermy 1980). With the development of science and technology, SEM is widely used in palynology, it is rapid, simple and accurate, and gives people a clear effect ( $\mathrm{Li}$ et al. 2019). The submicroscopic structure of spore morphology of different taxa pteridophytes under SEM is of great significance in taxonomy, which provides a palynological basis for the establishment of new species ( $\mathrm{Li}$ and Ding 1988, Li et al. 1989). The submicroscopic structure of spores of D. lijianxiuii X. J. Li under SEM was studied. The results showed that the spore perispore of D. lijianxiuii X. J. Li had tuberculiform-rugulate protrusions, and surfaces with melting ice and snow ornamentation (Fig. 3: A-D), the spore perispore of D. lacera (Thunb.) O. Kuntze had tuberculiform protrusions, and surfaces with scaly ornamentation (Fig. 3E-H), the differences of spore ornamentation characteristics provide the submicroscopic structure basis for the establishment of new species of D. lijianxiuii X. J. Li.

\section{Acknowledgments}

This work was supported by the "One belt, one road" national traditional herbal medicine back-ground database and construction project (2018FY100702), National Key Research and Development Program of China (2017YFC1700703), and Shandong Provincial Natural Science Foundation Project (ZR2020QC021). The authors thank Prof. Jianxiu Li from Shandong University of Traditional Chinese Medicine for the revision of the manuscript.

\section{References}

Chen HB 1990. Flora of Shandong. Qingdao Publishing House (Qingdao).

China Flora Editorial Board of Chinese Academy of Sciences 2000. Flora Reipublicae Popularis Sinicae 5(1). Science Press (Beijing) 187-201.

Ding ZC, Zhou FQ and Li JX 1990. Study on the morphogenesis of intercellular space glandularhairs of Dryopteris. J. Shandong Univ. TCM. 14(1): 45-46.

Editorial committee of Flora of China 2013. Flora of China 2-3. Science Press (Beijing) \& Missouri Botanical Garden Press (St Louis) 603-606.

Fu LG, Hong T, Lin Q 2008. Higher plants of China. Qingdao Publishing House (Qingdao) 487-533

Instituto botanico academiae sinicae instituto botanico boreali-occidentali academiae sinicae edita 1974. Flora tsinlingensis (Tomus II). Science Press (Beijing) 1.

Jermy AC. 1980. Biosystematic studies of Dryopteris. Acta phytotax Sin. 18(1): 37-44.

Li FZ 1985. A new species of Dryopteris from Shandong. Bulletin of Botanical Research. 5(1):157-159.

Li JX and Ding ZC 1988. Two new species of Athyriopsis from Shandong province. Acta Phytotaxonomica Sinica.26(2): 162-164.

Li JX, Ding ZC and Zhou FQ 1989. Studies on spore morphology of Athyriopsis Ching in Shandong. Bulletin of Botanical Research. 9(3): 105-112.

Li JX and Li F 1988. A new species of Dryopteris from Shandong. Acta Phytotaxonomica Sinica. 26(5): 406407.

Li JX and Ma ST 1983. One new species of Dryopteris from Laoshan, Shandong Province. Bulletin of Botanical Research. 3(4): 139-141.

Li JX, Zhou FQ, Zhang YC 1997. The significance of pollen morphological characteristics in the new taxonomy by SEM //Editorial Board of Science and Education Series. The Volume of the Chinese Science and Education. Hongqi Press (Chengdou). 944-945.

Li XJ, Ding JJ, Li JX, et al. 2019. Palynology and anatomy of Dryopteris Adans. from Shandong, China and their significance in classification. Bangladesh J. Bot. 48(3): 877-884.

Lu JM, Li DZ and Wu D 2007. Spore morphology of the family Dryopteridaceae. ActaBotanica Yunnanica. 29(4): 397-408. 
Thiers B 2016. Index Herbariorum: A global directory of public herbaria and associated staff. NewYork Botanical Garden's Virtual Herbarium. http://sweetgum.nybg.org/ih/

Wang QX and Dai XL 2010. Study on the spore morphology of Polypodiales (Filicales) from China. Science Press (Beijing) 224.

Warre H and Wagner Jr 1974. Annals of the Missouri Botanical Garden. 61: 332.

Wen J and Nowicke JW 1999. Pollen ultrastructure of Panax(the ginseng genus, Araliaceae), an eastern Asian and eastern North American disjunct genus. American J. Bot. 86: 1624-1636. https://doi.org/ $10.2307 / 2656799$

Wu S, Jianying X, Lu S, Faguo W, Xing F, Dong S, Hai H, Zhang L, Barrington DS and Christenhusz MJM 2013. Dryopteris Adans. Flora of China. vol. 2-3: 571.

Zhang JT 1979. Some groups of classification and phylogeny were discussed on the basis of the pollen morphological characters. Acta Phytotaxonomica Sinica 17(2): 1-7.

Zhang LB, Wang PS and Wang XY 2012. Dryopteris liboensis (Dryopteridaceae), New Species in Dryopteris sect. Erythrovariae from Guizhou, China. Novon 22: 256-259.

Zhang YL and Xi YZ. 1976. Chinese ferns spore morphology. Science Press (Beijing) 188-189.

Zhou FQ, Li JX and Ding ZC 1985. Preliminary observation on the anatomy of the petiole base of Dryopteris from Shandong. J. Shandong Univ. TCM. 9: 38-42.

(Manuscript received on 19 May, 2021; revised on 20 August, 2021) 